\title{
Failure Mechanisms of Lead-Free Chip Scale Package Interconnections under Fast Mechanical Loading
}

\author{
T.T. MATTILA ${ }^{1}$ and J.K. KIVILAHTI ${ }^{1,2}$ \\ 1.-Department of Electrical \& Communications Engineering, Helsinki University of Technology, \\ Espoo, FIN-02015 TTK, Finland. 2.—E-mail: jorma.kivilahti@hut.fi
}

The reliability of chip scale package (CSP) components against mechanical shocks has been studied by employing statistical, fractographic, and microstructural research methods. The components having high tin $(\mathrm{Sn} 0.2 \mathrm{Ag} 0.4 \mathrm{Cu})$ solder bumps were reflow soldered with the $\mathrm{Sn} 3.8 \mathrm{Ag} 0.7 \mathrm{Cu}$ (wt.\%) solder paste on $\mathrm{Ni}(\mathrm{P}) \mid \mathrm{Au}-$ and organic solderability preservative (OSP)-coated multilayer printed wiring boards (PWBs), and the assemblies were subjected to the standard drop test procedure. The statistically significant difference in the reliability performance was observed: the components soldered on $\mathrm{Cu}$ |OSP were more reliable than those soldered on $\mathrm{Ni}(\mathrm{P}) \mid \mathrm{Au}$. Solder interconnections on the $\mathrm{Cu} \mid$ OSP boards failed at the component side, where cracks propagated through the $(\mathrm{Cu}, \mathrm{Ni})_{6} \mathrm{Sn}_{5}$ reaction layer, whereas interconnections on the $\mathrm{Ni}(\mathrm{P}) \mid \mathrm{Au}$ boards failed at the PWB side exhibiting the brittle fracture known also as "black pad." In the first failure mode, which is not normally observed in thermally cycled assemblies, cracks propagate along the intermetallic layers due to the strong strain-rate hardening of the solder interconnections in drop tests. Owing to strain-rate hardening, the stresses in the solder interconnections increase very rapidly in the corner regions of the interconnections above the fracture strength of the ternary $(\mathrm{Cu}, \mathrm{Ni})_{6} \mathrm{Sn}_{5}$ phase leading to intermetallic fracture. In addition, because of strain-rate hardening, the recrystallization of the as-soldered microstructure is hindered, and therefore the network of grain boundaries is not available in the bulk solder for cracks to propagate, as occurs during thermal cycling. In the black pad failure mode, cracks nucleate and propagate in the porous NiSnP layer between the columnar two-phase $\left(\mathrm{Ni}_{3} \mathrm{P}+\mathrm{Sn}\right)$ layer and the $(\mathrm{Cu}, \mathrm{Ni})_{6} \mathrm{Sn}_{5}$ intermetallic layer. The fact that the $\mathrm{Ni}(\mathrm{P}) \mid \mathrm{Au}$ interconnections fail at the PWB side, even though higher stresses are generated on the component side, underlines the brittle nature of the reaction layer.

Key words: Lead-free, reliability, printed wiring board (PWB) metal finish, Weibull analysis, failure mechanisms, twinning, strain-rate hardening, recrystallization

\section{INTRODUCTION}

As portable electronic devices become functionally and structurally increasingly complex, good reliability performance is a major requirement. The products must sustain, in addition to thermomechanical stresses generated by heat dissipating elements, different kinds of dynamic mechanical stresses in their service environments. At the same time, as

(Received July 8, 2004; accepted December 27, 2004) component technologies used in the portable products, such as chip scale packages (CSP), employ increasing interconnection densities and thus decreasing interconnection volumes, shock impacts to these products are becoming a notable reliability concern. ${ }^{1}$ Because portable products are more likely to be dropped than affected by changes in thermal conditions, the emphasis of reliability research is gradually shifting from studying the effects of thermomechanical cycling to mechanical shock loading or power cycling. 
Along with this development, new requirements for environmentally friendly electronics production have also been raised worldwide. This concerns especially the removal of lead from consumer electronics within the European Union by the July 1, 2006. ${ }^{2,3}$ The most favorable material combination for leadfree soldering would be plain copper conductors and pure tin solder. However, owing to too high melting point-from the reflow soldering point of view-and inadequate mechanical properties of pure Sn, this relatively simple solution is presently not used in volume production. Most lead-free solder candidates are based on Sn with two or more major alloying elements. Similarly, plain copper is hardly ever used as board or component metallization due to the oxidation of copper at room temperature under atmospheric conditions. Thus, lead-free surface finishes on copper soldering pads, such as gold on nickel-phosphorous $\mathrm{Ni}(\mathrm{P})$ metallization or organic solderability preservative (OSP), are required. The employment of these surface finish materials together with various lead-free bump and solder materials will lead to new multimaterial interconnection systems and generate also new materials compatibility issues that need to be solved for the sake of reliability. Accordingly, the continuing miniaturization, increased component power, and environmentally friendly lead-free production will create additional requirements for investigating the reliability of portable electronics especially under mechanical shock-loading conditions.

Only few papers have been published on the board level reliability of high-density assemblies under drop conditions. ${ }^{4-7}$ Results from these studies show that the intermetallic layers between the solder and contact metallizations are prone to fail in the drop tests, and therefore the properties of the intermetallic layers are in a particularly important position for the reliability of portable electronics. Intermetallic reactions between lead-free solders and various metallizations have been studied widely. Especially, the reactions between $\mathrm{Ni}(\mathrm{P}) \mid \mathrm{Au}$-coated soldering pads and solders have been studied extensively. ${ }^{8-17}$ Likewise, the cracking of interconnections soldered on the $\mathrm{Ni}(\mathrm{P})$ metallization has also been reported in these papers and the occurrence of the failure is typically explained by the oxidation or contamination of the plating bath that affects the quality of the metallization.

Hence, because high local stresses and more complex stress distributions caused by mechanical shocks are encountered in modern portable electronic equipments, failure modes and mechanisms controlling the reliability of the CSP interconnections under shock loading conditions are of great interest and importance, and therefore they will be investigated in this article. The reliability is being studied by employing a large number of test structures and by investigating statistically the differences between times to failure. Detailed fractographic and microstructural studies will be carried out in order to obtain a better understanding of the failure modes and mechanisms.

\section{MATERIALS AND METHODS}

The component was a CSP-sized $\mathrm{Sn} 0.2 \mathrm{Ag} 0.4 \mathrm{Cu}$ bumped $12 \mathrm{~mm} \times 12 \mathrm{~mm}$ ball grid array packaged (BGA) component having 500- $\mu \mathrm{m}$ bump diameter and $800-\mu \mathrm{m}$ pitch. The height of the bumps was $480 \mu \mathrm{m}$. The number of bumps per component was 144 and the weight of the component was about $0.3 \mathrm{~g}$.

The high-density circuit boards $(1+6+1$ build-up FR4) were manufactured by Aspocomp Group (Salo, Finland) with two different protective coating options on the $\mathrm{Cu}$ soldering pads: $\mathrm{Ni}(\mathrm{P}) \mid \mathrm{Au}$ [Ni: $2 \mu \mathrm{m}, \mathrm{Au}$ : $\sim 0.02 \mu \mathrm{m}, 9 \mathrm{wt} . \% \mathrm{P}$ in Ni] and OSP $(0.2-0.5 \mu \mathrm{m})$. The test board was designed according to the JEDEC board level drop test standard (JESD22-B111). ${ }^{18}$

The circuit boards were assembled using Sn3.8 $\mathrm{Ag} 0.7 \mathrm{Cu}$ (Multicore, Munich, Germany) solder paste. The solder paste was printed (DEK 265 Horizon, Weymouth, UK) with a $100-\mu \mathrm{m}$-thick electroformed Ni stencil and metal squeegees. The mounting machine (Philips ACM Micro, Eindhoven, Netherlands) was set to achieve the highest possible accuracy $(\mu+5 \sigma<30$ $\left.\mu \mathrm{m}, \mathrm{C}_{\mathrm{pk}}=1.67\right)$ and the reflow was carried out in a conventional forced convection oven (EPM/Heraeus EWOS $5.1 \mathrm{~N}_{2}$, Hanau, Germany) under air atmosphere. The temperature profile was set according to the recommendations of the solder paste manufacturer. The peak temperature underneath the CSP component was measured with the profilometer (ECD Super M.O.L.E. Gold, Milwaukie, OR) as $241^{\circ} \mathrm{C} \pm 0.5^{\circ} \mathrm{C}$, and the time above $217^{\circ} \mathrm{C}$ was $50 \mathrm{sec} \pm 1 \mathrm{sec}$ depending on the component location.

After the post-reflow inspection, the assemblies were drop tested according to the JESD22-B111 standard. Two deviations from the standard were made. (a) Multiple drops due to the bounce back after the initial impact were not eliminated because no means were available to do this. The first bounce back was about $30 \%$ of the initial drop height. (b) $1.5 \mathrm{k} \Omega$ resistance through the daisy chain network was used as the failure criterion instead of $1 \mathrm{k} \Omega$, in order to exclude the noise inherent in the measurements. The drop test equipment is composed of a fixture where the circuit boards are attached, a sledge that holds the fixture, and a rigid strike surface. The sledge travels up and down on guide rods. The drop height was set to $82 \mathrm{~cm}$ in order to achieve the peak deceleration of $1,500 \mathrm{~g}$ for the duration of $0.5 \mathrm{~ms}$ (half-sine pulse) required by the standard. The test boards were mounted on support pins with screws at the four corners of the board (Fig. 1). The components faced downward during the test. Strains on the test board were measured (National Instruments PXI6052E/SCI-1520/SCI-1314, Austin, TX) with strain gauges $(1 \mathrm{~mm} \times 1 \mathrm{~mm})$ attached on the PWB on several locations, two of which are shown in Fig. 1 (SG). The strain gauges were attached on the opposite side of the board relative to the components. Deceleration was measured (PXI-4472) simultaneously. The event 


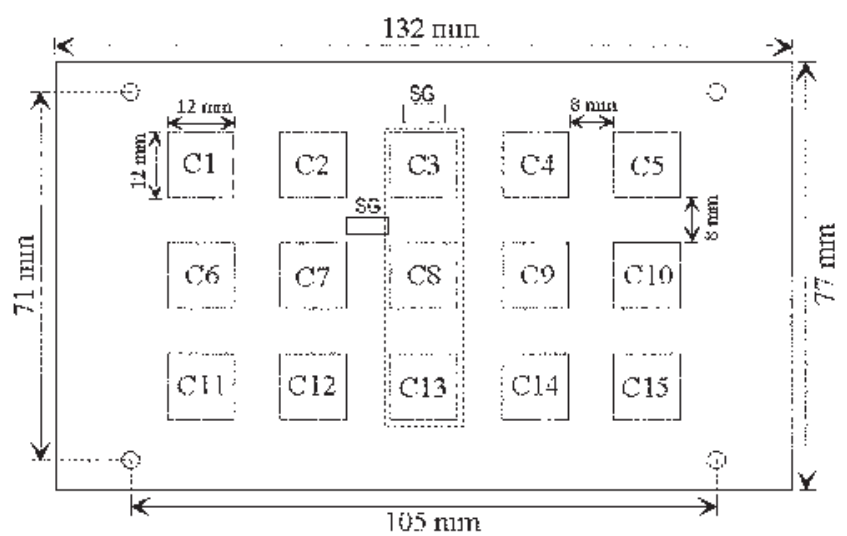

Fig. 1. Layout and dimensions of the drop test board.

detector was connected to the test boards by soldering. A failure was recorded when the resistance through the daisy chain network exceeded the threshold resistance for $200 \mathrm{~ns}$ three times in a sequence of five drops. All electrical connections were checked before interpreting the increase as a failure. The assemblies were dropped until all components had failed in order to obtain enough statistical data for the Weibull analysis. The primary failure mechanism was determined from additional assemblies that were dropped until the first failure.

The failure mechanisms were studied from cross sections prepared by standard metallographic methods. Cross sections were investigated with optical (Olympus BX60, Tokyo, Japan) and scanning electron (JEOL 63 35F, Tokyo, Japan) microscopes. Polarized light was used in the optical microscope because the reflection is dependent on grain orientation, and thus differently oriented grains appear in the micrographs in different colors. The distributions of elements at the interconnection reaction zones were analyzed by the energy-dispersive x-ray spectroscopy (Oxford, INCA). The as-soldered interfaces were further characterized by transmission electron microscopy (TEM, JEOL 2000FX, Tokyo, Japan). The TEM studies were undertaken to investigate the structure of the PWB side interfacial region of the solder interconnections on the $\mathrm{Ni}(\mathrm{P}) \mid \mathrm{Au}$ boards.

The reliability of the solder interconnections was studied by making use of the statistical Weibull reliability analysis. The three-parameter cumulative Weibull distribution function is given by

$$
\mathrm{F}(\mathrm{t})=1-\exp \left[-\left(\frac{\mathrm{t}-\gamma}{\eta}\right)^{\beta}\right]
$$

where $F(t)$ is the cumulative density function, $\eta$ is the characteristic lifetime, $\beta$ is the shape parameter, and $\gamma$ is the failure free lifetime. Because the $\beta$ parameter is dependent on the failure rate, the failure mechanisms can be identified by its value. If the failure data plots with a concave trend and the fit of the regression is therefore poor, this may indicate the presence of a failure free lifetime and the third parameter $\gamma$ should be introduced. Otherwise, the $\gamma$ equals zero. The difference in reliability performance is evaluated on the basis of average drops-to-failure. Parametric methods require the assumption that the data are normally distributed. The test for normality can be carried out by the Shapiro-Wilk test, for instance, which calculates a $\mathrm{W}$ statistic, which is given by

$$
\mathrm{W}=\frac{\left(\sum_{\mathrm{i}=1}^{\mathrm{n}} \mathrm{a}_{\mathrm{i}} \mathrm{x}_{\mathrm{i}}\right)^{2}}{\sum_{\mathrm{i}=1}^{\mathrm{n}}\left(\mathrm{x}_{\mathrm{i}}-\overline{\mathrm{x}}\right)}
$$

where $x_{i}$ is the ordered sample value and $a_{i}$ is a constant generated from the mean, variance, and covariance of the order statistics from a normal distribution. ${ }^{19}$ The $\mathrm{W}$ statistic approaches one for normally distributed samples. When the drops-to-failure does not follow the normal distribution, nonparametric methods must be used to test the equality of two populations. The Wilcoxon Rank-Sum Test procedure is the most widely used test for such purposes. ${ }^{20}$

\section{RESULTS AND DISCUSSION}

The drop tests were carried out with two different coating options on the test boards with ten replications of each. In order to make use of as many data points as possible in Weibull analysis, the locations where the components experience nearly equal mechanical loadings were determined on the basis of the drops-to-failure, strain measurements, and finiteelement modeling (FEM). Three middle components (components on C3, C8, and C13 in Fig. 1) were pooled to form a single sample per coating option. To validate the pooling of component locations, the tensile stresses in the interconnections at different component locations during the test were calculated by FEM. ${ }^{4}$ To confirm the results of the FE calculation, the strains of the board were measured. Figure 2 shows the measured and calculated longitudinal strain histories during the first bending. The stain histories in Fig. 2 show that, although the measured strains are higher than the calculated ones, the maximum value is of the

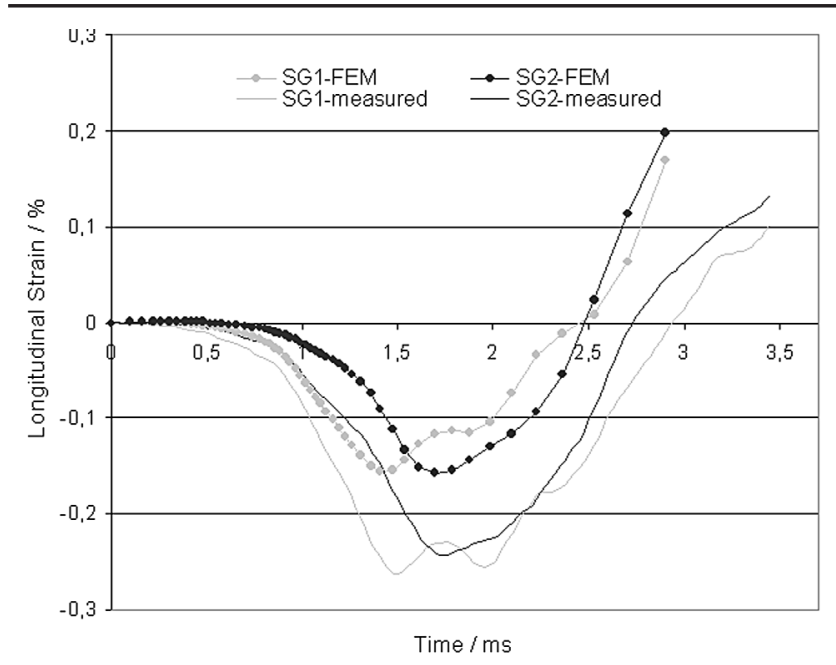

Fig. 2. Comparison of the measured and calculated longitudinal strains on the board at two different locations (Fig. 1). 
same magnitude for both locations. The difference in the median drops-to-failure was also studied separately for both coating options using the Wilcoxon Rank-Sum Test, and no significant differences could be found. Figure 3 presents the Weibull plots of the $\mathrm{Ni}(\mathrm{P}) \mid \mathrm{Au}-$ and $\mathrm{Cu} \mid \mathrm{OSP}-$ assemblies. The decision to use the two- or three-parameter form of the Weibull distribution was based on the goodness-of-fit test.

The characteristic lifetimes $(\eta)$ were 7 and 13 drops, and the shape parameters $(\beta)$ with $95 \%$ confidence intervals were $1.8 \pm 0.2$ and $1.4 \pm 0.1$ for the $\mathrm{Ni}(\mathrm{P}) \mid \mathrm{Au}$ and $\mathrm{Cu} \mid \mathrm{OSP}$ assemblies, respectively. The failure free lifetime in the case of Cu|OSP assemblies was two drops. Because the significance of the differences between the $\eta$ values cannot be tested statistically, it must be evaluated by other means. Based on the Shapiro-Wilk Test for normality, neither the $\mathrm{Ni}(\mathrm{P}) \mid \mathrm{Au}-$ nor the $\mathrm{Cu}$ |OSP- assemblies had normally distributed drops-to-failure distribution. Therefore, nonparametric methods must be used to infer difference in their reliability performance. In engineering sciences, the statistical confidence levels of more than 95\% can typically be considered sufficient to reject the null hypothesis, and therefore, all the tests in this paper are carried out at less than 5\% risk level. The result of the Wilcoxon Rank-Sum Test points out that the $\mathrm{Cu}$ |OSP pad metallization gives significantly better reliability at the $0.01 \%$ risk level. The significance between the beta parameters should be tested as well. Therefore, the $95 \%$ confidence interval of the difference in the beta parameters was calculated. The confidence interval for the difference is $0.37 \pm 0.31$, and thus, the difference is statistically significant; i.e., the analysis suggests that the failure mechanisms are different in the two combinations.
The failure analyses revealed that the electrical breakdown of the components' daisy-chain structures was caused by brittle fracture at one or the other of the opposite interfacial regions of the solder interconnections: the region between the bulk solder and soldering pad or the region between the bulk solder and the component side metallization. The interconnections soldered on the $\mathrm{Ni}(\mathrm{P}) \mid \mathrm{Au}$ failed from the PWB side along a complex reaction product layer between the $\mathrm{Ni}(\mathrm{P})$ metallization and the $(\mathrm{Cu}, \mathrm{Ni})_{6} \mathrm{Sn}_{5}$ intermetallic compound layer, whereas those soldered on $\mathrm{Cu}$ |OSP pads failed from the component side $(\mathrm{Cu}, \mathrm{Ni})_{6} \mathrm{Sn}_{5}$ layer.

Since the as-soldered microstructure contains only a few large colonies, the high-angle boundaries of which are rarely located at the corner regions of the interconnections, the structure does not provide potential sites for cracks to nucleate and propagate in the bulk solder without recrystallization. ${ }^{21}$ However, the detailed microscopic studies executed after the reliability testing revealed no traces of the recrystallization even after several months of storage at room temperature.

The differences between the failure mechanisms being operative during fast mechanical loadings and in thermal cycling tests can be explained as follows: The drop tests were carried out at room temperature $(\sim 295 \mathrm{~K})$, which is relatively high $\left(0.6 \mathrm{~T}_{\mathrm{MR}}\right)$ as compared to the melting range (MR) of the solder alloy ( $\sim 490-500 \mathrm{~K})$. Therefore, the flow stress of solder interconnections is strongly dependent on the strain rate, as shown in Fig. $4{ }^{22,23}$ The solder alloys become remarkably stronger as the strain rate increases from that occurring in thermal cycling tests $\left(\sim 10^{-3}\right.$ $\% / \mathrm{sec})$ to that used in drop tests $\left(\sim 10^{3} \% / \mathrm{sec}\right)$.
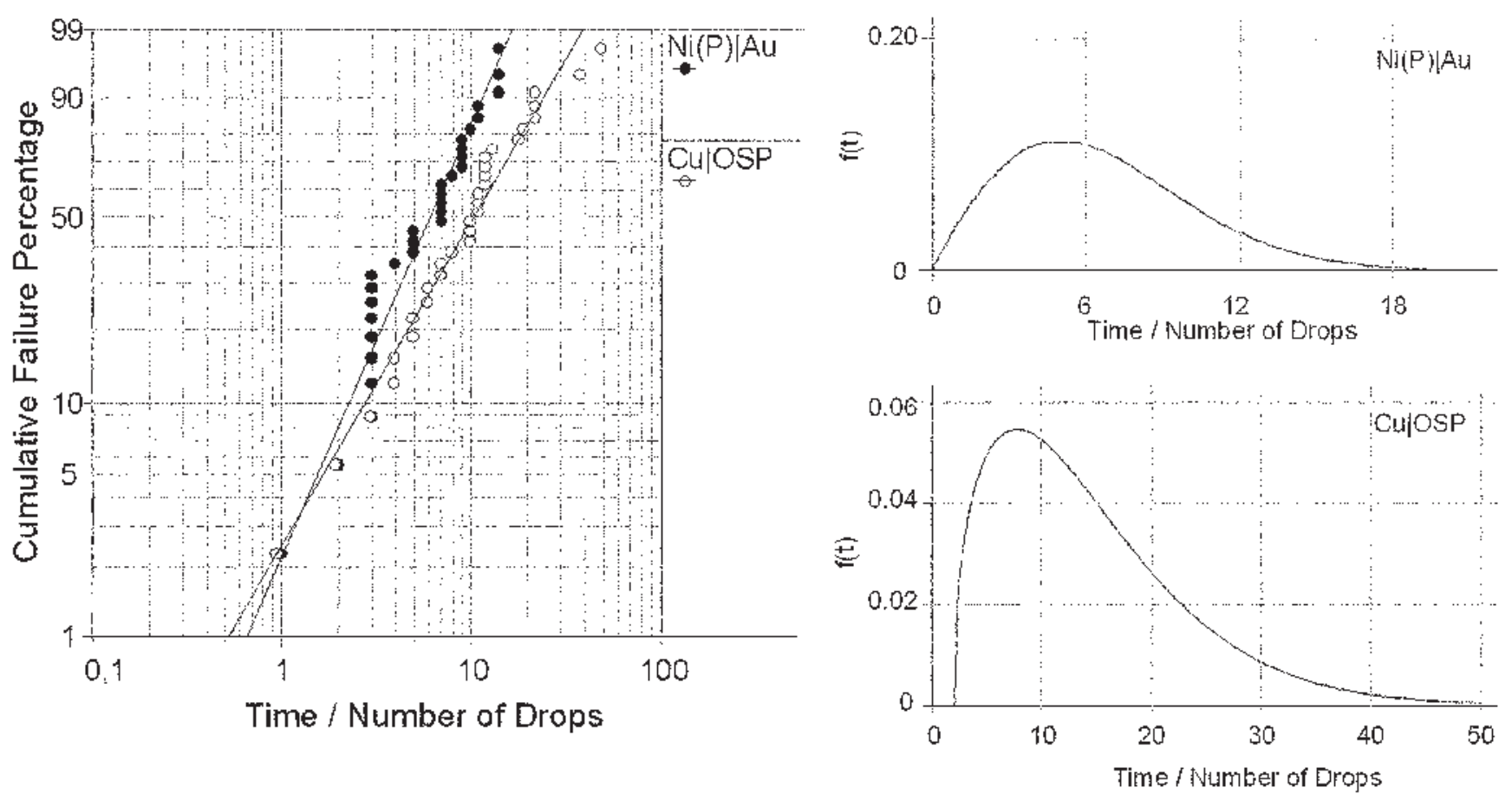

Fig. 3. Weibull reliability plots and the probability density functions for the CSPs on different protective coatings 


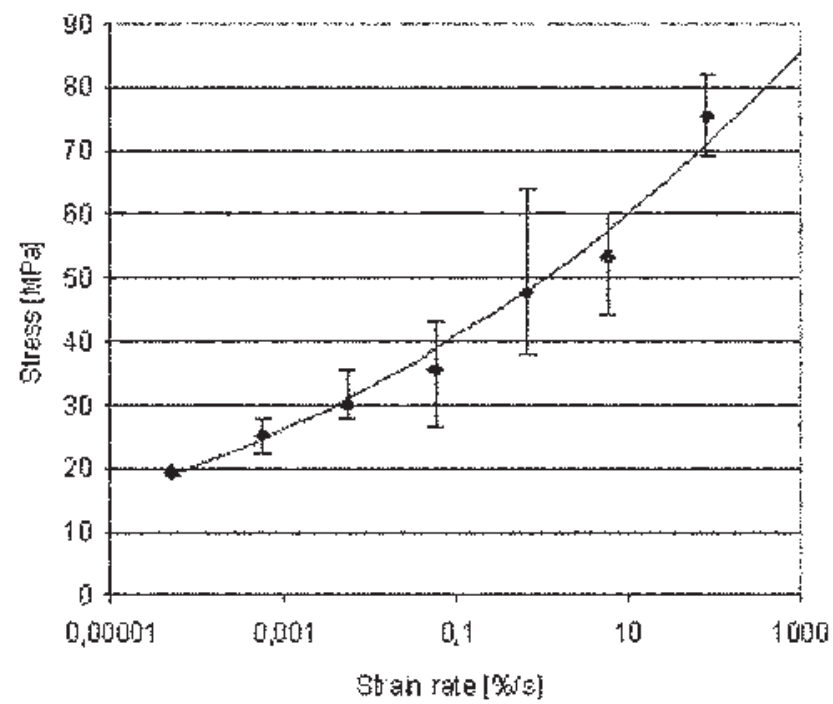

Fig. 4. Flow stress versus strain rate of a Sn2Ag0.5Cu solder joint at room temperature.

According to Fig. 4, the flow stresses of solder materials are expected to be about 2 to 3 times higher in drop tests than in the thermal cycling test. Due to strain-rate hardening, the solder interconnections do not have time for marked plastic deformation, and the critical reduction (i.e., degree of deformation) needed for the recrystallization is not exceeded. The fact that plastic deformation occurring by dislocation slip is limited under shock loading conditions is evidenced also by the presence of numerous deformation twins. It has been reported that as the strain rate is increased, the twinning becomes the dominant deformation mechanism at the expense of slip. ${ }^{24}$ The deformation twins are typically observed at the corner regions of the interconnections (Fig. 5) where stresses are also the highest. It has been measured that the flow stresses in the range of 7-25 $\mathrm{MPa}$ are required to nucleate twins in $\mathrm{Sn}$ at room temperature, and considerably smaller stresses are needed for further thickening of the twins. ${ }^{25}$ Thus, due to the strain-rate hardening of the solder interconnections, the stresses become much higher and more concentrated in the corner regions of interconnections, ${ }^{4}$ where they exceed the fracture strength of the weakest reaction layer. Therefore, cracks propagate in the reaction layers, instead of the bulk solder, as typically observed after thermal cycling.

\section{Cu | OSP Assemblies}

The components' under bump metallization consisted of $\sim 0.6-0.8-\mu \mathrm{m}$-thick electrochemical $\mathrm{Ni}$ on the top of which there had been a very thin layer of gold. The gold layer dissolves completely into the solder bumps during the reflow bumping stage. So, during the assembly reflow, the molten $\mathrm{SnAgCu}$ solder becomes in contact with the component side $\mathrm{Ni}$ layer, and the first phase to form at the $\mathrm{Ni}$ | solder interface is $(\mathrm{Cu}, \mathrm{Ni})_{6} \mathrm{Sn}_{5}$. The reasons for the formation of $\mathrm{Cu}_{6} \mathrm{Sn}_{5}$, instead of expected $\mathrm{Ni}_{3} \mathrm{Sn}_{4}$, have been discussed elsewhere. ${ }^{8}$ The morphology of

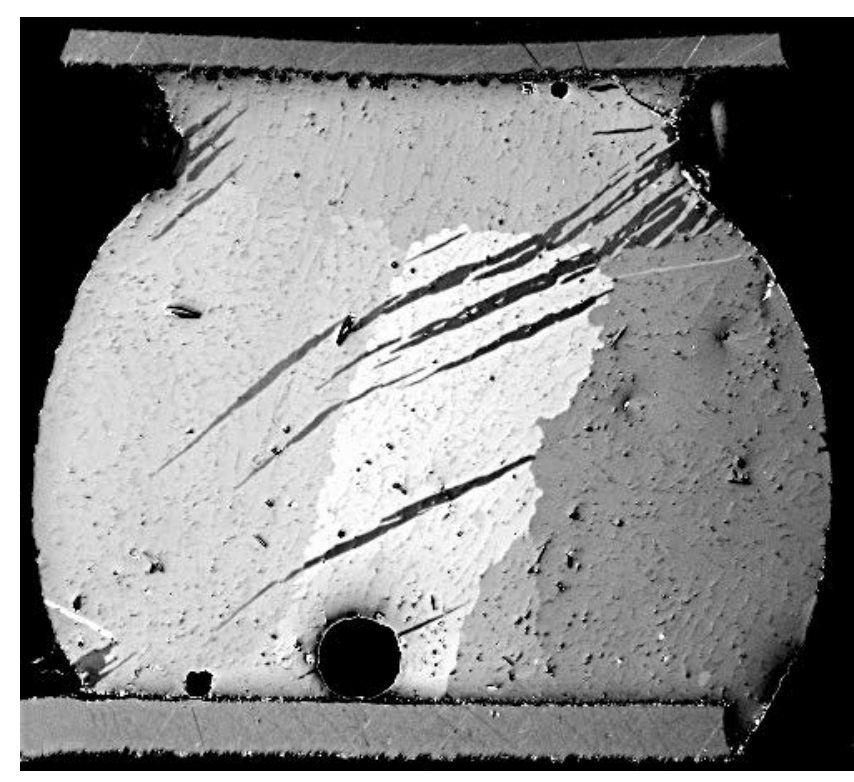

Fig. 5. Structure of the bulk solder after drop test: mechanical twins in the cellular solidification structure.

the reaction layer is typically of scallop type. The relatively thick, also scallop shaped, and irregular intermetallic compound layer visible on the PWB side is the binary $\mathrm{Cu}_{6} \mathrm{Sn}_{5}$. A very thin layer of $\mathrm{Cu}_{3} \mathrm{Sn}$ can be also observed with light optically as well as with scanning electron microscopy (SEM) between $\mathrm{Cu}$ pads and $\mathrm{Cu}_{6} \mathrm{Sn}_{5}$

The micrograph taken using SEM (Fig. 6) shows the typical component side failure, where the crack has propagated through the ternary $(\mathrm{Cu}, \mathrm{Ni})_{6} \mathrm{Sn}_{5}$ layer. In all the failures observed, the cracks have nucleated-for geometric reasons-in the bulk solder a short distance away from the $(\mathrm{Cu}, \mathrm{Ni})_{6} \mathrm{Sn}_{5}$ layer and then moved to this intermetallic layer, which obviously provides a favorable path for brittle fracture. Some minor cracking was also observed in the PWB side reaction zone of the interconnections. However, in all the cases studied, the cracks, which caused the electrical failures, located at the component side reaction zone.

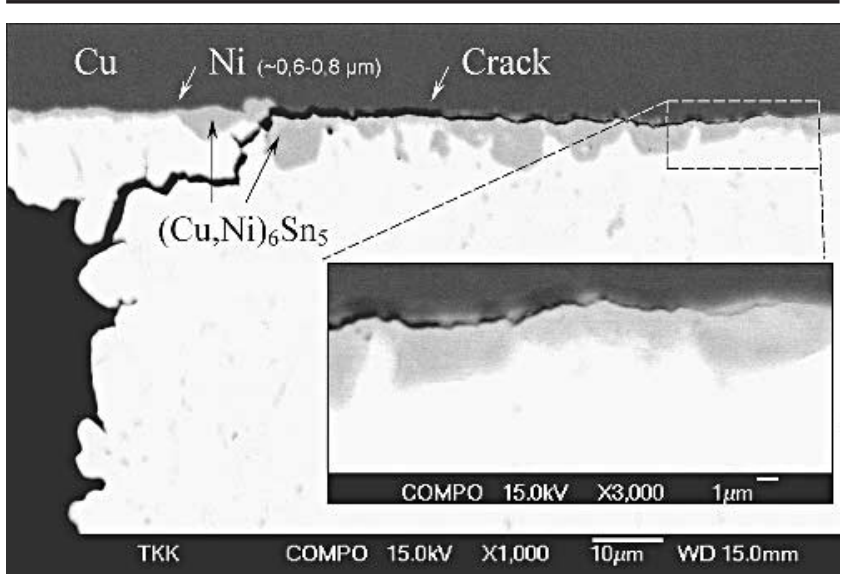

Fig. 6. The primary failure mode in the $\mathrm{Cu}$ |OSP interconnections: the cracking of the component side $(\mathrm{Cu}, \mathrm{Ni})_{6} \mathrm{Sn}_{5}$ layer. 
The effect of additional elements in the reaction between $\mathrm{Cu}$ and $\mathrm{Sn}$ has been reported in the literature. ${ }^{26-28}$ The addition of $\mathrm{Ni}$ has been observed to have a minor impact on the formation and thickness of the intermetallic compound layer, but it produces severe cracking of the intermetallic phase. Kulojärvi ${ }^{28}$ noted in her thesis that $\mathrm{Ni}$ weakens the mechanical properties of $\mathrm{Cu}_{6} \mathrm{Sn}_{5}$. The cracking of the $(\mathrm{Cu}, \mathrm{Ni})_{6} \mathrm{Sn}_{5}$ was occasionally visible even in the after reflow reference samples. The brittle nature of the $(\mathrm{Cu}, \mathrm{Ni})_{6} \mathrm{Sn}_{5}$ compound is further emphasized by small secondary cracks seen sometimes branching out from the primary path.

The effect of $\mathrm{Ni}$ on the mechanical properties of $\mathrm{Cu}_{6} \mathrm{Sn}_{5}$ is being studied, and the results will be published later. It is interesting to note, however, that according to our most recent TEM studies, Ni will also precipitate as $\mathrm{Ni}_{3} \mathrm{Sn}_{4}$ phase inside $(\mathrm{Cu}, \mathrm{Ni})_{6} \mathrm{Sn}_{5}$. The identification of the solubility of the precipitated phase at room temperature must be done and the question of whether the $(\mathrm{Cu}, \mathrm{Ni})_{6} \mathrm{Sn}_{5}$-matrix is then stable (the ordered long-period superlattice) or metastable (the simple $\eta$-form of the NiAs structure) remains to be solved.

The cracks on the PWB side of the interconnections propagate mostly in the $\mathrm{Cu}_{6} \mathrm{Sn}_{5}$ layer, as shown in Fig. 7. It is typical that the cracks propagated progressively with the number of drop impacts. Furthermore, cracks on the PWB side are not very common. As discussed previously, the complete fracture is always found on the component side, where the cracking is typically much more severe. It is therefore concluded that the fracturing of the PWB side intermetallic layers $\left(\mathrm{Cu}_{6} \mathrm{Sn}_{5}\right.$ or $\left.\mathrm{Cu}_{3} \mathrm{Sn}\right)$ is not the primary mechanism for electrical failure of the $\mathrm{Cu}$ |OSP assemblies.

\section{$\mathrm{Ni}(\mathrm{P}) \mid$ Au Assemblies}

During electroless coating of the PWB solder pads, $\mathrm{Ni}$ is deposited together with phosphorus, because the hydrophosphite is used as a reducing agent in the plating bath. On the top of the $\mathrm{Ni}(\mathrm{P})$ coating, there is a thin $\mathrm{Au}$ layer to protect the $\mathrm{Ni}$ from oxidation and

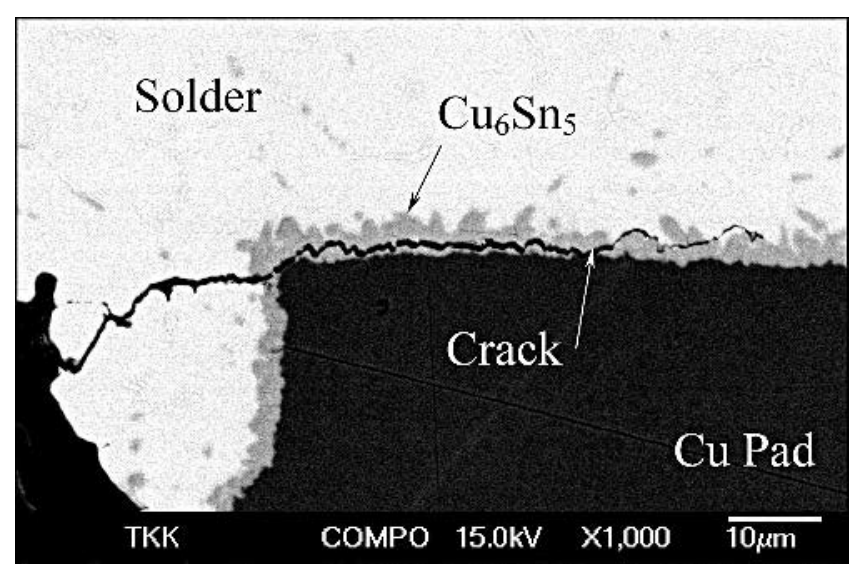

Fig. 7. Fracture in the PWB side $\mathrm{Cu}_{6} \mathrm{Sn}_{5}$ of the Cu|OSP interconnection. thereby to promote solderability. During soldering, a thin layer of $\mathrm{Au}$ dissolves instantly into molten solder and $(\mathrm{Cu}, \mathrm{Ni})_{6} \mathrm{Sn}_{5}$ is formed on the $\mathrm{Ni}(\mathrm{P})$ layer.

The $\mathrm{Ni}(\mathrm{P}) \mid \mathrm{Au}$ assemblies, unlike the $\mathrm{Cu} \mid \mathrm{OSP}$ assemblies, exhibit severe cracking in the PWB side. The results of the FEM of the CSP interconnections show that in drop tests, the stresses at the component side interfacial region are more than two times as large as those on the PWB side due to the geometry of the interconnections and the materials used. ${ }^{4}$ Therefore, the fact that the interconnections fail at the PWB side emphasizes the brittle nature of the reaction layer. The cracks propagate in a very narrow reaction zone between the two-phase layer (dark gray) and the $(\mathrm{Cu}, \mathrm{Ni})_{6} \mathrm{Sn}_{5}$ intermetallic layer, as shown in Fig. 8. Further support for this observation can be obtained from the distributions of the elements over the cracked region, even though the concentration profiles can be taken only qualitatively because of the crack interfaces. Figure 9 presents the energydispersive spectroscopy (EDS) line analysis of the $\mathrm{P}$ and Sn concentrations across a crack. The crack can be located in the graph, where the $\mathrm{P}$ and Sn concentrations decrease considerably (between about $4.5 \mu \mathrm{m}$ and $5 \mu \mathrm{m}$ in the abscissa). The two-phase layer and electroless $\mathrm{Ni}(\mathrm{P})$ are to the left from the indicated location of the crack, and to the right there is a solder interconnection.

With the help of TEM, it was discovered that the interfacial region between $\mathrm{Ni}(\mathrm{P})$ and $(\mathrm{Cu}, \mathrm{Ni})_{6} \mathrm{Sn}_{5}$ is composed on two layers, as shown in Fig. 10. The dark phase in Fig. $8 \mathrm{~b}$ is the two-phase layer of $\mathrm{Ni}_{3} \mathrm{P}$ and $\mathrm{Sn}$. In this two-phase layer, Sn (white stripes) is located between columnar $\mathrm{Ni}_{3} \mathrm{P}$ crystals. Between the two-phase layer and $(\mathrm{Cu}, \mathrm{Ni})_{6} \mathrm{Sn}_{5}$, there is a porous microcrystalline (or amorphous) phase layer, which
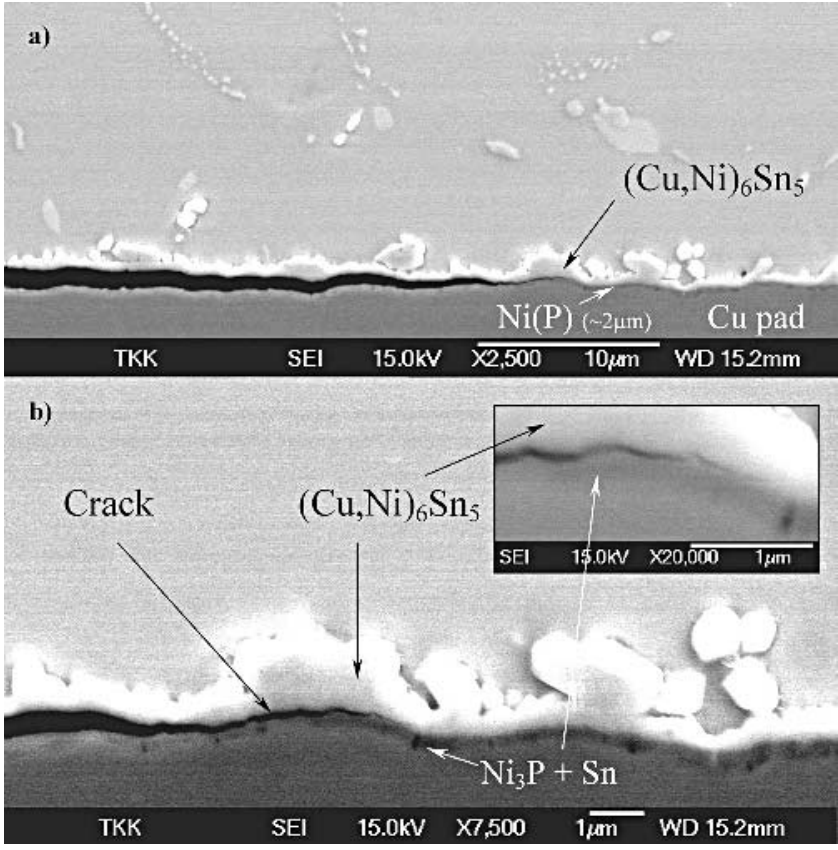

Fig. 8. Tip of the crack between the $(\mathrm{Cu}, \mathrm{Ni})_{6} \mathrm{Sn}_{5}$ and the two-phase layer on the $\mathrm{Ni}(\mathrm{P})$ coating. 


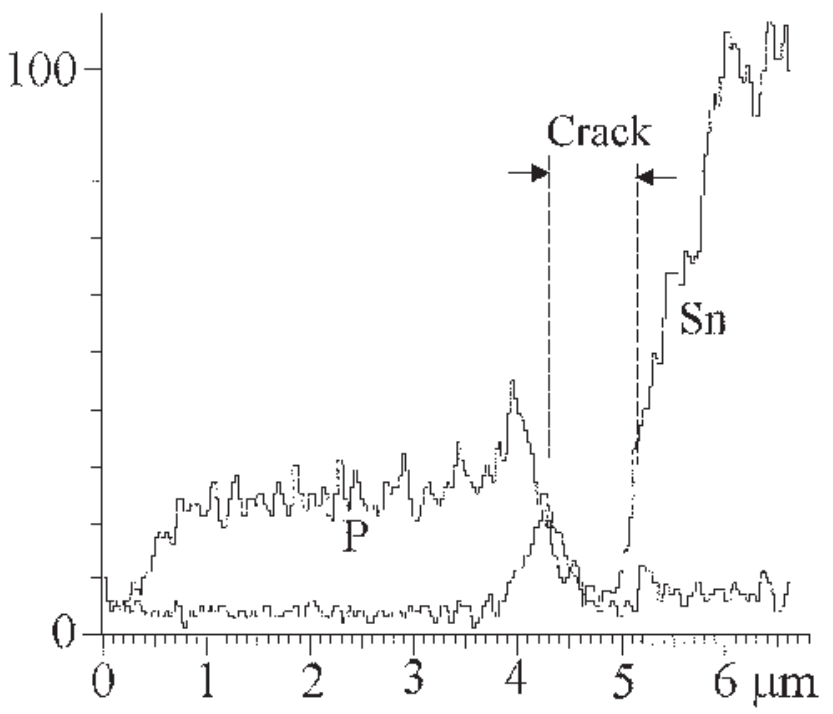

Fig. 9. EDS line scans of tin and phosphorous across a crack.

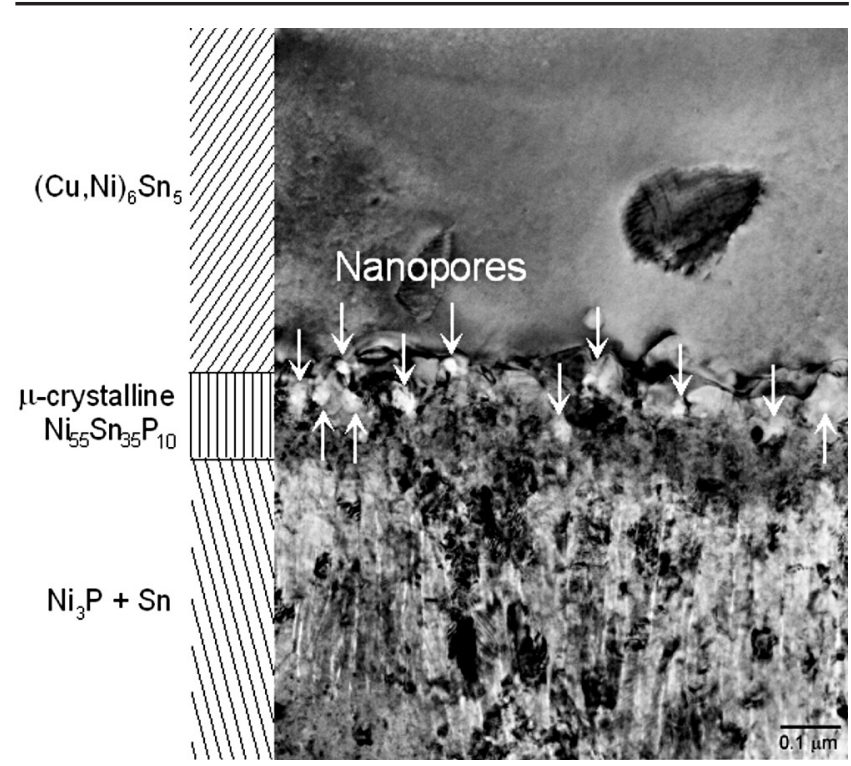

Fig. 10. Bright-field image of the reaction zone between electroless $\mathrm{Ni}(\mathrm{P})$ metallization and the near-eutectic $\mathrm{SnAgCu}$ solder (magnification: $100,000 \times)$. Between the Ni3P and Sn two-phase layer, there is a thin porous ternary solution phase containing nickel, tin, and phosphorus.

contains nickel, tin, and phosphorus. It is this thin layer in which the cracks are located (Fig. 8) in the case of the $\mathrm{Ni}(\mathrm{P}) \mid \mathrm{Au}$ coating. The formation of these P-induced reaction products has been discussed in more detail elsewhere. ${ }^{9}$

Thus, based on the SEM/EDS and TEM studies, it can be concluded that the brittle rupture of the porous ternary phase in between the $(\mathrm{Cu}, \mathrm{Ni})_{6} \mathrm{Sn}_{5}$ and the columnar two-phase $\left(\mathrm{Ni}_{3} \mathrm{P}+\mathrm{Sn}\right)$ layer is the primary failure mechanism in the case of the $\mathrm{Ni}(\mathrm{P}) \mid \mathrm{Au}$ assemblies.

\section{CONCLUSIONS}

The reliability of the lead-free CSP component has been studied by using a very high loading rate in the drop test as well as by employing statistical, fracto- graphic, and microstructural research methods. Two different failure modes were observed: the interconnections on the $\mathrm{Ni}(\mathrm{P}) \mid \mathrm{Au}$-coated soldering pads failed from the PWB side-along the porous reaction layer-whereas the interconnections on the OSPcoated pads failed from the component side $(\mathrm{Cu}, \mathrm{Ni})_{6}$ $\mathrm{Sn}_{5}$ intermetallic layer. These failure modes differ from those being characteristic for thermally cycled solder interconnections. The local recrystallization of solder interconnections, typical for thermally cycled interconnections, enhances cracks to nucleate in and propagate through the bulk solder interconnections. However, no recrystallization was observed in the drop-tested assemblies. Most obviously the critical reduction needed for the onset of recrystallization is not exceeded in drop tests, because the solder interconnections hardly deform plastically due to strong strain-rate hardening under very fast deformation. Owing to the strain-rate hardening, the stresses at the corner regions of the interconnections increase locally above the fracture strengths of the interfacial reaction layers, and therefore, the interconnections fail either by intermetallic fracture or by the cracking of the porous ternary phase. It seems evident that dissolved $\mathrm{Ni}$ lowers the fracture strength of $\left(\mathrm{Cu}, \mathrm{Ni}_{6}\right) \mathrm{Sn}_{5}$. Likewise, high phosphorous content in the electroless Ni layer may have a detrimental effect on the reliability of lead-free interconnections, when tested under mechanical shock loading conditions.

\section{ACKNOWLEDGMENTS}

The authors are indebted to Dr. Tomi Laurila and Mr. Pekka Marjamäki for useful discussions. We also thank the National Technology Agency of Finland, Aspocomp Group, Atotech GmbH, Elcoteq Network, Micro Analog Systems, and Nokia for their financial support.

\section{REFERENCES}

1. V. Puligandla, S. Dunford, and J.K. Kivilahti, Reliability Aspects of Lead-Free Solders in Electronic Assemblies, the Handbook of Lead (Pb)-Free Technology for Microelectronics Assemblies, ed. Karl J. Puttliz and Kathleen A. Stalter (New York: Marcel Dekker Inc., 2004), pp. 769-850.

2. Directive 2002/96/EC of European Parliament and the Council on Waste of Electrical and Electronic Equipment (WEEE), 27.1.2003.

3. Directive 2002/96/EC of the European Parliament and the Council on the Restriction of the Use of Certain Hazardous Substances in Electrical and Electronic Equipment/RoHS), 27.1.2003.

4. T.T. Mattila, P. Marjamäki, and J.K. Kivilahti, Reliability of CSP Interconnections Under Mechanical Shock Loading Conditions, (submitted 2005).

5. K. Mishiro, S. Ishikawa, M. Abe, T. Kumai, Y. Higashiguchi, and K. Tsebone, Microelectron. Reliability 42, 77 (2002).

6. K. Kujala and M. Kulojärvi, Package Miniaturization Options and Challenges for Baseband IC's. The Proceeding of IMAPS Nordic Annual Conference, (Espoo, Finland, IMAPS, September 21-24, 2003).

7. T.Y. Tee, H.S. Ng, C.T. Lim, E. Pek, and Z. Zhong, Board Level Drop Test and Simulation of TFBGA Packages for Telecommunication Applications. The Proceedings of the 53rd Electronic Components and Technology Conference (Piscataway, NJ: IEEE, 2003), pp. 121-129. 
8. K. Zeng, V. Vuorinen, and J.K. Kivilahti, The Proc. of the 51st IEEE Electronic Components and Technology Conference. (Piscataway, NJ: IEEE, 2001), pp. 693-698.

9. V. Vuorinen, T. Laurila, Y. Hao, T.T. Mattila, and J.K. Kivilahti, Phase Formation between Lead-Free $\mathrm{SnAgCu}$ Solder and Ni(P)/Au Finishes (submitted 2005).

10. Y.D. Jeon, S. Nieland, A. Ostmann, H. Reichl, and K.W. Paik, J. Electron. Mater. 32, 548 (2003).

11. J. Haimovich, Welding J. 68, 102s (1989).

12. C.E. Ho, S.Y. Tsai, and C.R. Kao, IEEE Trans. Adv. Packaging 24, 493 (2001).

13. P. Su, T. Korhonen, M. Korhonen, and C.Y. Li, Intermetallic Phase Formation and Growth Kinetics at the Interface Between Molten Solder and Ni-Containing Under Bump Metallization. The Proceedings of the Electronic Component and Technology Conference. (Piscataway, NJ: IEEE, 2000), pp. 1712-1718.

14. H. Matsuki, H. Ibuka, and H. Saka, Sci. Technol. Adv. Mater. 3, 261 (2002)

15. Z. Mei, M. Kaufmann, A. Eslambolchi, and P. Johnson: Brittle Interfacial Fracture of PBGA Packages Soldered on Electroless Nickel/Immersion Gold. The Proceedings of the Electronic Components and Technology Conference. (Piscataway, NJ: IEEE, May 25-28, 1998), pp. 952-961.

16. Y.D. Jeon, K.W. Paik, K.S. Bok, W.S. Choi, and C.L. Cho: J. Electron. Mater. 31, 520 (2002).
17. Y.D. Jeon and K.W. Paik, The Proceeding of the Electronic Components and Technology Conference. (Piscataway, NJ: IEEE, 2001), pp. 1326-1332.

18. JESD22-B111, Board Level Drop Test Method of Components for Handheld Electronic Products (Arlington, VA: JEDEC Solid State Technology Association, July 2003).

19. Engineering Statistics Handbook, NIST/SEMATECH e-Handbook of Statistical Methods, http://www.itl.nist.gov/ div898/handbook/, 20.1.2005.

20. J.S. Milton and J.C.Arnold, Introduction to Probability and Statistics, 2nd ed. (New York: McGraw-Hill, 1990), pp. 324-326.

21. T.T. Mattila, V. Vuorinen, and J.K. Kivilahti, J. Mater. Res. 19, 3214 (2004).

22. T.O. Reinikainen, P. Marjamäki, and J.K. Kivilahti, The Proceedings of the 6th IEEE EuroSim Conference (Piscataway, NJ: IEEE, 2005).

23. J.K. Kivilahti, (Presentation at IMAPS Nordic Conf., Espoo, Finland, 21-24 September 2003).

24. K. Ishii, J. Phys. Soc. Jpn. 14, 1315 (1959).

25. P. Oberndorff (Doctoral Thesis, Eindhoven University of Technology, 2001).

26. T. Takemoto and T. Yamamoto, J. JCBRA, 40, 309 (2001).

27. H. Rhee, F. Guo, J.G. Lee, K.C. Chen, and K.N. Subramanian, J. Electron. Mater. 32, 1257 (2003).

28. L.L. Ye (Doctoral Thesis, Chalmers University of Technology, 2002). 